\title{
ANÁliSE POR CROMATOGRAFIA GASOSA DE BTEX NAS EMISSÕES DE MOTOR DE COMBUSTÃo INTER- NA ALIMENTADO COM DIESEL E MISTURA DIESEL-BIODIESEL (B10)
}

Sérgio L. Ferreira*, Antônio M. dos Santos e Gustavo R. de Souza

Departamento de Engenharia Mecânica, Escola de Engenharia de São Carlos, Universidade de São Paulo, $13566-590$ São

Carlos - SP, Brasil

Wagner L. Polito

Instituto de Química de São Carlos, Universidade de São Paulo, 13560-970 São Carlos - SP, Brasil

Délson L. Módolo

Fundação Hermínio Ometto (UNIARARAS), Av. Dr. Maximiliano Baruto, 500, 13607-339 Araras - SP, Brasil

Recebido em 16/2/07; aceito em 20/9/07; publicado na web em 10/3/08

\begin{abstract}
ANALYSIS OF BTEX IN THE EMISSIONS FROM AN INTERNAL COMBUSTION ENGINE BURNING DIESEL OIL AND DIESEL-BIODIESEL MIXTURE (B10) BY GAS CHROMATOGRAPHY. This paper describes the procedures for analysing pollutant gases emitted by engines, such as volatile organic compounds (benzene, toluene, ethylbenzene, o-xylene, m-xylene and p-xylene) by using high resolution gas chromatography (HRGC). For IC engine burning, in a broad sense, the use of the B10 mixture reduces drastically the emissions of aromatic compounds. Especially for benzene the reduction of concentrations occurs at the level of about $24.5 \%$. Although a concentration value below $1 \mu \mathrm{g} \mathrm{mL} \mathrm{m}^{-1}$ has been obtained, this reduction is extremely significant since benzene is a carcinogenic compound.
\end{abstract}

Keywords: emissions; fuels; gas chromatography.

\section{INTRODUÇÃO}

Com o progresso, urbanização, crescimento da população, desenvolvimento de novas tecnologias e uma elevada frota de veículos automotores observa-se um progressivo aumento na taxa de emissões de poluentes atmosféricos e, em conseqüência, isto gera grandes problemas ambientais.

A identificação de uma fonte de poluição atmosférica depende, antes de tudo, dos referenciais para definir os agentes poluidores e seus efeitos sobre homens, animais, vegetais ou outros materiais, assim como dos critérios para medir a freqüência da ocorrência dos poluentes e seus efeitos. ${ }^{1}$

As atividades humanas são poluidoras e, com muita freqüência, quantidades imensas dos poluentes resultantes dessas atividades são lançadas na atmosfera.

Hoje em dia, nas cidades, as emissões veiculares desempenham um papel de destaque no nível de poluição do ar na RMSP (Região Metropolitana de São Paulo), pois emitem gases como: compostos orgânicos voláteis (COV), monóxido de carbono $(\mathrm{CO})$, óxidos de nitrogênio $\left(\mathrm{NO}_{\mathrm{x}}\right)$, óxidos de enxofre $\left(\mathrm{SO}_{\mathrm{x}}\right)$, gases ácidos, entre outros. ${ }^{2}$

Desse modo, as pessoas estão expostas a poluentes em concentrações suficientes e tão duradouras que podem causar um aumento na probabilidade de adquirir câncer ou sentir outros efeitos sérios de saúde. ${ }^{3}$ Estes efeitos de saúde podem trazer danos ao sistema imunológico bem como neurológico, reprodutivo (fertilidade reduzida) e respiratório entre outros problemas graves. ${ }^{4}$

Dentre os compostos orgânicos voláteis salientam-se os BTEX (benzeno, tolueno, etilbenzeno, o-xileno, m-xileno e p-xileno) que podem ou não ser carcinogênicos como citado anteriormente e, além disso, podem ter efeitos neurotóxicos e/ou mutagênicos.

Muitos estudos sobre emissão, transporte e deposição dos poluentes atmosféricos têm sido feitos buscando-se soluções para o controle e a

*e-mail: serggiolf@yahoo.com.br diminuição da poluição do ar dos grandes centros urbanos. ${ }^{5,6}$

Também, nas últimas décadas, grande parte das pesquisas está voltada para responder questões relacionadas aos efeitos dos poluentes sobre ecossistemas de florestas. ${ }^{7}$

\section{Combustível tradicional}

Diesel

O óleo diesel é um combustível de composição complexa derivado do petróleo, constituído basicamente por hidrocarbonetos parafínicos, olefínicos e aromáticos e, em menor quantidade, por substâncias cuja fórmula química contém átomos de enxofre, nitrogênio, metais, oxigênio, entre outros.

A faixa de destilação comumente é entre $220-380{ }^{\circ} \mathrm{C}$. Este derivado é utilizado em motores automotivos de combustão interna por compressão.

O óleo diesel é formulado por meio da mistura de diversas correntes como gasóleos, nafta pesada, diesel leve e diesel pesado, provenientes das diversas etapas de processamento do petróleo bruto. A Petrobras produz Óleo Diesel tipo B, Óleo Diesel tipo D e Óleo Diesel Marítimo, que são entregues diretamente às Companhias Distribuidoras.

Devido à sua alta eficiência, durabilidade e flexibilidade há uma tendência mundial de utilização crescente destes motores na indústria automobilística, o que reflete num aumento da demanda por diesel em relação aos demais derivados de petróleo. A máquina a diesel é a que alcança os maiores rendimentos (cerca de 45\%) comparada com as demais de combustão interna. ${ }^{8,9}$

O ciclo diesel é regulado apenas pela vazão de combustível, uma vez que a vazão de ar permanece constante com as mudanças de velocidade do motor. Como os motores a diesel geralmente operam com excesso de oxigênio, as emissões de hidrocarbonetos e de monóxido de carbono são minimizadas, ${ }^{10}$ porém, entre os principais poluentes emitidos por esses motores destacam-se os materi- 
ais particulados que são uma das maiores causas de poluição em grandes centros urbanos. ${ }^{2}$

O óleo diesel possui uma série de padrões de especificação, sendo que os que mais afetam a emissão de poluentes são: o número de cetano, teor de enxofre, teor de aromáticos e a densidade. ${ }^{11}$

\section{Combustível alternativo}

\section{Biodiesel}

Desde a primeira crise petrolífera em 1973, a biomassa passou a ser considerada e, em alguns casos, promovida como alternativa ao combustível fóssil como fonte de energia.

Atenção particular foi atribuída ao potencial de utilização da biomassa como base para a produção de combustíveis alternativos para veículos a motor (motores diesel ou a gasolina), dada a quase exclusiva dependência do setor dos transportes em relação ao petróleo. ${ }^{12}$

Um dos combustíveis é o biodiesel que, de modo geral, foi definido pela National Biodiesel Board dos Estados Unidos como "o derivado mono-alquil éster de ácidos graxos de cadeia longa, proveniente de fontes renováveis como óleos vegetais ou gordura animal, cuja utilização está associada à substituição de combustíveis fósseis em motores de ignição por compressão" (motores do ciclo Diesel). ${ }^{13}$

Segundo Ramos, ${ }^{14}$ pode-se dizer que o biodiesel tem as seguintes características: é virtualmente livre de enxofre e aromáticos, tem alto número de cetano, possui teor médio de oxigênio em torno de $11 \%$, possui maior viscosidade e maior ponto de fulgor que o diesel convencional, possui nicho de mercado específico, diretamente associado a atividades agrícolas, tem preço de mercado relativamente superior ao diesel comercial.

De acordo com a Environmental Protection Agency (EPA), ${ }^{15}$ um grande número de estudos das emissões do biodiesel foi avaliado. Uma parte dos resultados das emissões do biodiesel são apresentados na Tabela 1.

Tabela 1. Emissões médias do biodiesel comparadas ao diesel

\begin{tabular}{lcc}
\hline TIPO DE EMISSÕES & B100 & B20 \\
\hline Regulados & & \\
\hline Hidrocarbonetos totais & $-67 \%$ & $-20 \%$ \\
não queimados & $-48 \%$ & $-12 \%$ \\
Monóxido de carbono & $-47 \%$ & $-12 \%$ \\
Material particulado & $+10 \%$ & $+2 \%$ \\
NO & & \\
\hline Não regulados & & $-20 \% *$ \\
\hline Sulfatos & $-100 \%$ & $-13 \%$ \\
Hidrocarbonetos policíclicos & $-80 \%$ & $-50 \% * * *$ \\
aromáticos (HPA)** & $-10 \%$ \\
HPA Nitrados** & $-50 \%$ & $-50 \%$ \\
Potencial de Ozônio do HC & $-10 \%$
\end{tabular}

* Estimado do resultado do B100. ** Redução média através de todos compostos medidos. ${ }^{* *}$ Resultados 2-nitrofluorino foram dentro da variabilidade do método teste

Na promoção dos biocombustíveis, o fato de se tratar de produtos mais onerosos pode ser contornado de diversas formas: apoio ao setor agrícola não-alimentar, diferenciação fiscal a favor dos biocombustíveis para torna-los competitivos no mercado e especificação de uma determinada quantidade de biocombustível nos combustíveis vendidos para transportes. ${ }^{12}$

Para a obtenção de biodiesel, utiliza-se a reação de transeste- rificação de óleos vegetais com álcoois primários.

Quimicamente, os óleos vegetais são triésteres ou triglicéridos naturais de ácidos graxos saturados ou insaturados, contendo cadeias de 8 a 24 átomos de carbono com diferentes graus de insaturação.

Conforme a espécie de oleaginosa, variações na composição química do óleo vegetal são expressas por variações na relação molar entre os diferentes ácidos graxos presentes na estrutura, e constituem uma fonte diversificada da base química dos biocombustíveis.

Existem milhares de ocorrências de produtos naturais desta grande família dos óleos vegetais. Do ponto de vista químico são três sub-categorias importantes: os óleos secantes, os óleos semisecantes e os óleos não secantes.

A reação de um óleo vegetal com álcoois pode ser conduzida tanto em meio ácido quanto em meio alcalino, conforme demonstrado no Esquema 1.

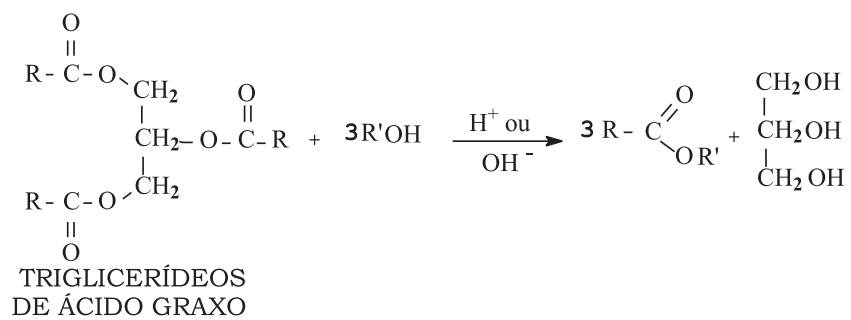

Esquema 1. Transesterificação de tri-acil-gliceróis (triglicerídeos ou triglicérides), sendo que R representa a cadeia carbônica dos ácidos graxos e R', a cadeia carbônica do álcool reagente

Geralmente, a reação de síntese empregada industrialmente utiliza uma razão molar óleo: álcool de 1:6 na presença de $0,4 \%$ de hidróxido de sódio ou de potássio, porque o meio básico apresenta melhor rendimento e menor tempo de reação que o meio ácido. ${ }^{16}$ Por outro lado, o excesso de agente transesterificante (álcool primário) faz-se necessário devido ao caráter reversível da reação.

$\mathrm{Na}$ Tabela 2 são mostradas as características de óleos vegetais comparadas com o óleo diesel. Na Tabela 3, mostram-se composições de ácidos graxos bem como número de ligações olefínicas (insaturação) de alguns óleos vegetais.

Portanto, a análise da composição de ácidos graxos constitui o primeiro procedimento para a avaliação preliminar da qualidade do óleo bruto e/ou de seus produtos de transformação e isto pode ser obtido através de vários métodos analíticos, tais como a cromatografia

Tabela 2. Propriedades físicas de óleos vegetais comparadas com o óleo diesel

\begin{tabular}{|c|c|c|c|c|c|}
\hline Características & $\begin{array}{l}\text { Dendê } \\
\text { polpa }\end{array}$ & Babaçu & Amendoim & Soja & $\begin{array}{c}\text { Óleo } \\
\text { Diesel }\end{array}$ \\
\hline $\begin{array}{l}\text { Poder Calorífico } \\
(\mathrm{kcal} / \mathrm{kg})\end{array}$ & 8946 & 9049 & 9458 & 9421 & 10950 \\
\hline Índice de Cetano & $38-40$ & 38 & $39-41$ & $36-39$ & 40 \\
\hline $\begin{array}{l}\text { Viscosidade a } \\
37,8^{\circ} \mathrm{C}(\mathrm{cSt})\end{array}$ & 36,8 & 30,3 & 41,1 & 36,8 & $2,0-4,3$ \\
\hline $\begin{array}{l}\text { Ponto de } \\
\text { Névoa }\left({ }^{\circ} \mathrm{C}\right)\end{array}$ & 31,0 & 26,0 & 19,0 & 13,0 & 0 \\
\hline $\begin{array}{l}\text { Temperatura de } \\
\text { destilação em }{ }^{\circ} \mathrm{C} \\
\text { para destilar } 90 \% \\
\text { do volume }\end{array}$ & 359 & 349 & 349 & 370 & 338 \\
\hline $\begin{array}{l}\text { Resíduo de } \\
\text { Carbono Conradson } \\
\text { sobre } 10 \% \text { do } \\
\text { resíduo (\% peso) }\end{array}$ & 0,54 & 0,28 & 0,49 & 0,54 & 0,35 \\
\hline
\end{tabular}


Tabela 3. Composição em ácidos graxos dos óleos de algumas espécies vegetais

\begin{tabular}{|c|c|c|c|c|c|c|c|}
\hline \multirow[t]{2}{*}{ Ácido graxo } & & \multirow{2}{*}{$\begin{array}{l}\text { Soja } \\
\text { Glycine } \\
\max \end{array}$} & \multirow{2}{*}{$\begin{array}{c}\text { Nabo } \\
\text { Forrageiro } \\
\text { Raphanus } \\
\text { sativus }\end{array}$} & \multirow{2}{*}{$\begin{array}{l}\text { Girassol } \\
\text { Helianthus } \\
\text { annuus }\end{array}$} & \multirow{2}{*}{$\begin{array}{c}\text { Mamona } \\
\text { Ricinus } \\
\text { communis }\end{array}$} & \multirow{2}{*}{$\begin{array}{c}\text { Dendê } \\
\text { (polpa) } \\
\text { Elaeis } \\
\text { guineensis }\end{array}$} & \multirow{2}{*}{$\begin{array}{c}\text { Dendê } \\
\text { (amêndoa) } \\
\text { Elaeis } \\
\text { guineensis }\end{array}$} \\
\hline & & & & & & & \\
\hline Caprílico & C8:0 & - & - & - & - & - & 3,3 \\
\hline Cáprico & C10:0 & - & - & - & - & - & 3,4 \\
\hline Láurico & $\mathrm{C} 12: 0$ & - & - & - & - & - & 48,2 \\
\hline Mirístico & $\mathrm{C} 14: 0$ & 0,3 & - & - & - & $1-6$ & 16,2 \\
\hline Palmítico & C16:0 & $7-11$ & 7 & 6 & 1 & $32-47$ & 8,4 \\
\hline Palmitolêico & C16:1 & $0-1$ & - & - & - & - & - \\
\hline Esteárico & $\mathrm{C} 18: 0$ & $3-6$ & 2 & 4,2 & 1 & $1-6$ & 2,5 \\
\hline Oléico & $\mathrm{C} 18: 1$ & $22-34$ & 22 & 18,7 & 3 & $40-52$ & 15,3 \\
\hline Ricinoléico & C18:1 & - & - & - & 89,5 & - & - \\
\hline Linoleico & $\mathrm{C} 18: 2$ & $50-60$ & 15 & 69,3 & 4,2 & $2-11$ & 2,3 \\
\hline Linolênico & $\mathrm{C} 18: 3$ & $2-10$ & 12 & 0,3 & 0,3 & - & - \\
\hline Aracdônico & $\mathrm{C} 20: 0$ & $5-10$ & 1 & 1,4 & - & - & - \\
\hline Behênico & $\mathrm{C} 22: 0$ & $5-10$ & - & - & - & - & - \\
\hline Eicosanóico & $\mathrm{C} 20: 1$ & - & 10 & - & 0,3 & - & - \\
\hline Erúcico & $\mathrm{C} 22: 1$ & - & 29 & - & - & - & - \\
\hline Lignocérico & $\mathrm{C} 24: 0$ & - & 1 & - & - & - & - \\
\hline Densidade a $15^{\circ} \mathrm{C}\left(\mathrm{g} / \mathrm{cm}^{3}\right)$ & & 0,927 & $0,916-0,918$ & 0,915 & 0,961 & 0,912 & 0,918 \\
\hline Índice de iodo & & 130,0 & $93-112$ & $110-143$ & 85,5 & 98 & $14-22$ \\
\hline Índice de saponificação & & 190,0 & $178-182$ & 188-194 & 180,3 & 197 & 248 \\
\hline
\end{tabular}

líquida de alta eficiência, ${ }^{17}$ a cromatografia gasosa ${ }^{18} \mathrm{e}$ a espectroscopia de ressonância magnética nuclear de hidrogênio. ${ }^{19}$

Outros tipos de materiais, como óleos vegetais e gorduras usadas em processos de fritura por imersão são, também, usados para a produção de biodiesel. Entretanto, estes sofrem degradação por reações tanto hidrolíticas quanto oxidativas. Neste caso, a oxidação, que é acelerada pela alta temperatura do processo, é a principal responsável pela modificação das características físico-químicas do óleo. Este óleo torna-se escuro, viscoso, tem sua acidez aumentada e desenvolve odor desagradável, comumente chamado de ranço. ${ }^{20}$

O óleo, depois de usado, torna-se um resíduo indesejado e sua reciclagem como biocombustível não só retiraria do meio ambiente um poluente, mas também permitiria a geração de uma fonte alternativa de energia. Assim, duas necessidades básicas seriam atendidas de uma só vez. ${ }^{21}$

Alguns pesquisadores investigaram a reação de transesterificação de óleos de fritura com metanol, etanol, n-propanol, isopropanol, nbutanol e 2-etoxietanol em meios ácido e alcalino. O maior rendimento foi obtido com metanol em meio alcalino, utilizando hidróxido de potássio como catalisador. Nesse mesmo estudo, alguns dos ésteres de menor viscosidade foram selecionados para a realização de testes preliminares em motores do ciclo diesel..$^{22}$

Observou-se que o éster metílico obtido em meio alcalino e os ésteres etílico e butílico obtidos em meio ácido não apresentaram problemas de ignição e desempenho, mostrando pouca fumaça na exaustão. Os demais ésteres não foram testados por critérios de viscosidade, e o rendimento da reação não serviu como parâmetro para a seleção dos ésteres a serem utilizados nos testes. ${ }^{22}$

\section{Emissões de motores movidos com uma mistura diesel- biodiesel}

A União Européia, em 2001, por razões ecológicas exigiu a diminuição do grau de dependência do petróleo por parte do setor de transportes (responsável por mais de $30 \%$ do consumo final de energia) por intermédio da utilização de combustíveis alternativos, como os biocombustíveis. ${ }^{12}$

Com os progressos tecnológicos, grande parte da frota de veículos atualmente em circulação na União Européia é capaz de usar sem qualquer problema misturas de baixo teor de biocombustível. Percebe-se uma tendência crescente no aumento da percentagem do biocombustível na mistura. Existem países em que se utilizam misturas com percentagens de $10 \%$ ou mais de biocombustíveis. ${ }^{12}$

A utilização acrescida de biocombustíveis nos transportes, a importância do cumprimento da legislação comunitária em matéria de qualidade dos combustíveis, emissões dos veículos e qualidade do ar, também faz parte do pacote de medidas necessárias para dar cumprimento ao Protocolo de Kyoto. ${ }^{12}$

A utilização de biodiesel como combustível representa um potencial promissor no mundo inteiro.

Em primeiro lugar, pela sua enorme contribuição ao meio ambiente, com a redução qualitativa e quantitativa dos níveis de poluição, e, em segundo lugar, como fonte estratégica de energia renovável em substituição ao óleo diesel e outros derivados do petróleo. ${ }^{14}$

Vários países investem pesado na produção e viabilização comercial do biodiesel, empregando unidades de produção com diferentes capacidades, distribuídas particularmente na Europa (França, Áustria, Alemanha, Bélgica, Reino Unido, Itália, Holanda, Finlândia e Suécia), na América do Norte (Estados Unidos) e na Ásia (Japão). ${ }^{23}$

De modo geral, a emissão de hidrocarbonetos proveniente da utilização do biodiesel de óleo de soja é inferior ao diesel convencional. Por exemplo, em motores turbinados, foi observada uma redução nominal de $40 \%{ }^{24}$

Por outro lado, ao serem comparadas às emissões de fumaça provenientes dos óleos diesel e vegetal transesterificado, verificou-se nitidamente que os menores índices corresponderam ao consumo de óleo transesterificado, principalmente acima de $4000 \mathrm{rpm}$. Esse comportamento, demonstrado para biodiesel de piqui, também foi observado para biodiesel de outras matérias-primas. ${ }^{25}$

No caso da combustão do biodiesel acredita-se que a emissão de aldeídos pode atingir valores 5-10 vezes maiores que os obtidos na combustão do diesel. Apesar disso, o número de mutações no teste de 
Ames (teste utilizado para detecção de mutação gênica) foi em média três vezes menor para o óleo vegetal que para o óleo diesel. ${ }^{24}$

No transporte rodoviário pesado oferece grandes vantagens para o meio ambiente, principalmente em grandes centros urbanos, tendo em vista que a emissão de poluentes é menor que a do óleo diesel. ${ }^{24,26-28}$

Recentemente, foi testada na frota de transporte coletivo da cidade de Curitiba a utilização de biodiesel de óleo de soja, doado pela American Soybean Association. O biodiesel foi misturado ao diesel convencional na proporção de $20 \%$, com o propósito de verificar a eficiência desse combustível na redução da poluição ambiental. ${ }^{29}$

Os resultados foram considerados bastante expressivos, considerando-se que apenas $20 \%$ dos ônibus que circulavam no terminal estavam abastecidos com a mistura B20.

Quanto à emissão de poluentes a partir de biodiesel de óleo usado em frituras, observou-se que os níveis de hidrocarbonetos, monóxido de carbono e materiais particulados foram inferiores ao diesel. ${ }^{30}$

Por outro lado, a avaliação da emissão de gases demonstrou que houve um aumento relativo na liberação de gases nitrogenados, particularmente quando o biocombustível foi comparado ao diesel convencional. $^{30}$

Chang et al. ${ }^{26}$ demonstraram que as emissões de monóxido e dióxido de carbono, enxofre e material particulado foram inferiores às do diesel convencional. No entanto, os níveis de emissões de gases nitrogenados foram maiores para diferentes tipos de biodiesel.

De acordo com Mittelbach e Tritthart, ${ }^{30}$ a utilização de biodiesel de óleos de fritura em motores do ciclo diesel apresentou bons resultados. Os testes foram feitos em bancada dinanométrica e em veículo de carga média com motor turbinado a diesel

A emissão de hidrocarbonetos e compostos policíclicos aromáticos (HPA) foi investigada por Mittelbach e Tritthart. ${ }^{30}$

Os principais HPA presentes nas emissões foram o fluoranteno e o pireno, que constituíram cerca de $70 \%$ do total analisado. Porém, foi também detectada a presença de outros componentes minoritários, como criseno, benzo(a)pireno, benzo(b)fluoranteno, indeno(1,2,3-cd)pireno, benzo(k)fluoranteno, benzo(ghi)perileno, antantreno e perileno, sendo que os quatro primeiros apresentam atividade biológica comprovada. ${ }^{30}$

No que tange a estes compostos, as emissões oriundas do biodiesel de óleo de fritura foram aproximadamente $28 \%$ superiores às do óleo diesel, mas não atingiram níveis considerados como críticos pela legislação européia. ${ }^{30}$

\section{PARTE EXPERIMENTAL}

\section{Equipamentos}

Balão volumétrico Pyrex de $10 \mathrm{~mL}$, béquer Pyrex de $10 \mathrm{~mL}$, bomba de vácuo Robinar Vacumaster-High Performance Vacuum Pump - capacidade de $93 \mathrm{~L} \mathrm{~min}^{-1}$, modelo 15401, cromatógrafo Shimadzu GC-17A, cromatógrafo Shimadzu (GC/MS-QP5000), motor de ignição por compressão IDI (injeção indireta), 1,9 L, 4 cilindros em linha, 79,5 × 95,5 mm (diâmetro e curso), alimentado por uma bomba injetora rotativa Bosch, aspirado, alimentado com óleo diesel e mistura diesel-biodiesel, acoplado a uma bancada dinanométrica Schenck Dynabar (Figura 1), pipeta graduada de 1, 5 e $10 \mathrm{~mL}$, sacos Tedlar para coleta de gases, seringa para injeção Agilent de $10 \mu \mathrm{L}$ e seringa para injeção de gases Agilent de $500 \mu \mathrm{L}$.

\section{Materiais}

Amostra padrão BTEX de $20 \mu \mathrm{g} \mathrm{mL}^{-1}$ Supelco para padronização do cromatógrafo, óleo diesel, gases coletados do motor de com-

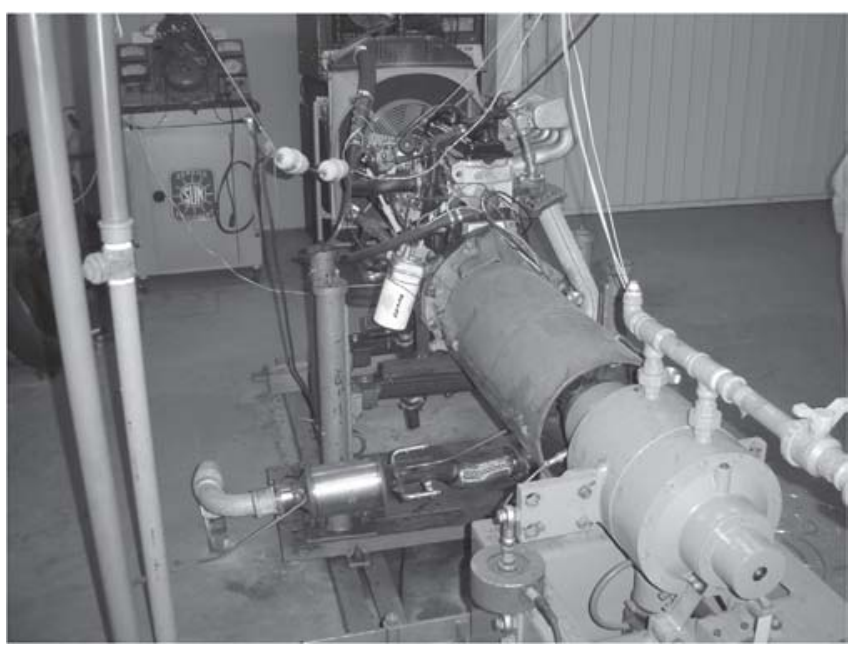

Figura 1. Motor de ignição por compressão movido a diesel e mistura dieselbiodiesel

bustão interna, gases utilizados no cromatógrafo: ar sintético, nitrogênio e hidrogênio da White Martins (grau de pureza FID), metanol 99,9\% (v/v) (grau cromatográfico) Mallinckrodt Baker S.A. e mistura diesel/biodiesel-Soyminas 90:10\% (v/v).

\section{Procedimento experimental}

\section{Padronização do cromatógrafo com os compostos BTEX}

Primeiramente, foi feito um estudo para estabelecer as melhores condições de programação de temperatura para se ter uma melhor resolução e separação dos picos para os compostos de interesse: benzeno, tolueno, etilbenzeno, o-xileno, m-xileno e p-xileno (BTEX). Depois de vários testes (rampas de aquecimento com as outras variáveis constantes) estabeleceram-se as condições de temperatura do forno que apresentavam melhor resolução na padronização do cromatógrafo com os compostos BTEX (Tabela 4).

Tabela 4. Condições cromatográficas de análise

\begin{tabular}{|c|c|}
\hline Coluna & DB-5 \\
\hline Fase estacionária & $5 \%$ fenil/95\% polidimetilsiloxano \\
\hline Comprimento & $60 \mathrm{~m}$ \\
\hline Diâmetro interno & $0,32 \mathrm{~mm}$ \\
\hline Espessura do filme & $1,0 \mu \mathrm{m}$ \\
\hline $\begin{array}{l}\text { Programa de } \\
\text { temperatura do forno }\end{array}$ & $\begin{array}{l}60^{\circ} \mathrm{C} \text { durante } 1 \mathrm{~min} / \\
7^{\circ} \mathrm{C} \text { min }^{-1} \text { até } 165^{\circ} \mathrm{C}\end{array}$ \\
\hline Detector & FID \\
\hline Temperatura do detector & $280^{\circ} \mathrm{C}$ \\
\hline Injetor & Split \\
\hline Temperatura do injetor & $220{ }^{\circ} \mathrm{C}$ \\
\hline Volume injetado & $1 \mu \mathrm{L}$ \\
\hline
\end{tabular}

Segundo a Osha, ${ }^{31}$ os limites de exposição aos BTEX são os apresentados na Tabela 5. Foi estabelecido o intervalo de concentrações das soluções preparadas para a padronização do cromatógrafo, principalmente com base no valor do limite de exposição do benzeno, que é de $1 \mu \mathrm{g} \mathrm{mL} \mathrm{L}^{-1}$.

Com isso, para a construção das curvas de padronização, foram preparadas soluções de 0,125 até $1 \mu \mathrm{g} \mathrm{mL} \mathrm{m}^{-1}$ a partir da amostra padrão de BTEX de $20 \mu \mathrm{g} \mathrm{mL}^{-1}$, observando que as proporções de cada composto são: $100 \%$ benzeno, $100 \%$ tolueno, $100 \%$ etilbenzeno, $60 \%$ m-xileno, $30 \%$ p-xileno e $10 \%$ o-xileno, ou seja, 20:20:20:12:6:2\% $\left(\mu \mathrm{g} \mathrm{mL}^{-1}\right)$, respectivamente. Para os cálculos dos 
Tabela 5. Limites de exposição dos compostos BTEX por $8 \mathrm{~h}$

\begin{tabular}{lc}
\hline Composto & Limite de exposição $\left(\mu \mathrm{g} \mathrm{mL} L^{-1}\right)$ \\
\hline Benzeno & 1 \\
Tolueno & 200 \\
Etilbenzeno & 100 \\
o-xileno & 100 \\
p-xileno & 100 \\
m-xileno & 100 \\
\hline
\end{tabular}

volumes de amostra para diluição utilizou-se a Equação 1.

$C_{1} V_{1}=C_{2} V_{2}$

sendo: $\mathrm{C}_{1}$ - concentração referência $\left(\mu \mathrm{g} \mathrm{mL} \mathrm{L}^{-1}\right) ; \mathrm{V}_{1}$ - volume desejado $(\mathrm{mL}) ; \mathrm{C}_{2}-$ concentração desejada $\left(\mu \mathrm{g} \mathrm{mL}^{-1}\right) ; \mathrm{V}_{2}$ - volume da diluição $(\mathrm{mL})$.

Após este procedimento, adicionou o volume desejado $\left(\mathrm{V}_{1}\right)$ das alíquotas de amostras e diluiu-se em metanol (grau cromatográfico) usando balões volumétricos de $10 \mathrm{~mL}$. Preparadas as soluções, em seguida, foram feitas injeções em quadruplicata para cada uma delas. Obtiveram-se os valores de área do pico para cada composto e com os valores de concentração de cada um deles, observando a porcentagem de cada composto na amostra padrão, construíram-se as curvas de padronização.

\section{Amostragem}

Para a amostragem dos gases emitidos pelo motor de ignição por compressão foram utilizados sacos Tedlar. Antes da coleta dos gases emitidos, os sacos Tedlar utilizados para coleta foram devidamente evacuados por uma bomba de vácuo para garantir que estavam totalmente vazios.

A Figura 2 mostra o sistema utilizado para a coleta dos gases provenientes da combustão do diesel e da mistura diesel-biodiesel no motor.

O motor utilizado no ensaio, alimentado com óleo diesel e mistura diesel-biodiesel (Figura 2) foi colocado em funcionamento por um período de $30 \mathrm{~h}$. Em seguida, foram coletados os gases emitidos na combustão utilizando sacos Tedlar, variando-se o parâmetro momento de força em três condições: 36,$1 ; 45,2$ e $57,6 \mathrm{~N} \mathrm{~m}$.

Utilizou-se um tempo de 10 min para a coleta de gases prove-

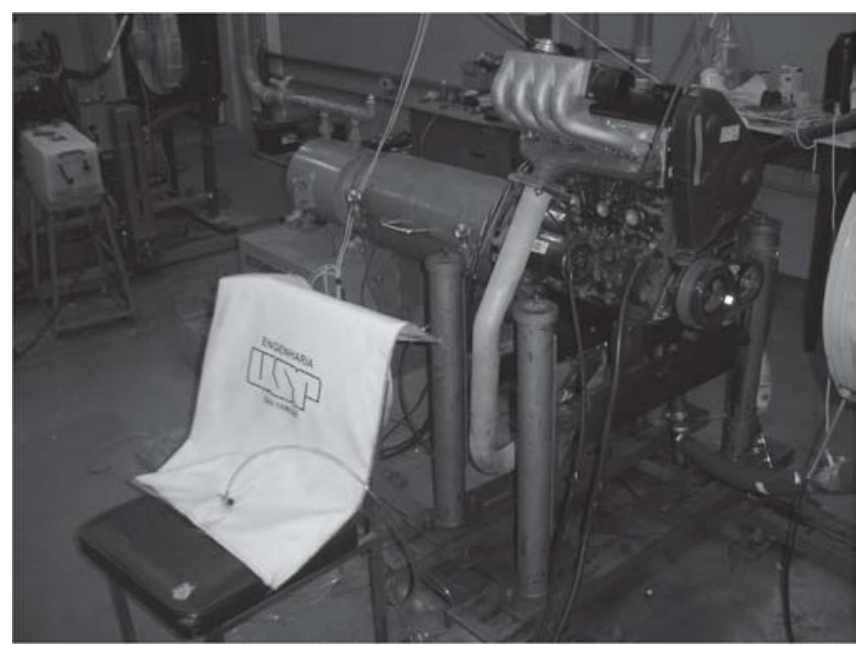

Figura 2. Coleta de gases do motor de ignição por compressão utilizando sacos Tedlar nientes do motor de ignição por compressão em sacos Tedlar, ou seja, até o enchimento na sua totalidade.

\section{Análise das amostras}

Os testes no cromatógrafo a gás para determinar os gases provenientes da combustão do diesel e da mistura diesel-biodiesel no motor foram feitos da seguinte forma: injetaram-se $400 \mu \mathrm{L}$ da amostra dos gases emitidos pelo motor, no modo split, submetendo-a uma programação de temperatura de: $60^{\circ} \mathrm{C}$ durante 1 min (isoterma) e com uma razão de aquecimento de $7{ }^{\circ} \mathrm{C} \min ^{-1}$ até a temperatura de $165{ }^{\circ} \mathrm{C}$. Foram analisados em um cromatográfo a gás de alta resolução (CGAR/FID) Shimadzu (GC-17A) utilizando uma coluna capilar DB-5 (5\% fenil e 95\% polidimetilsiloxano, $\mathrm{L}=60 \mathrm{~m}, \mathrm{D}$ $=0,32 \mu \mathrm{m}, \mathrm{di}=1,0 \mu \mathrm{m})$, equipado com um injetor na coluna e um detector por ionização em chama (DIC). Também, os gases emitidos foram analisados em um cromatógrafo (CG/EM) Shimadzu (GC/MS-QP5000).

\section{RESULTADOS E DISCUSSÃO}

\section{Padronização do cromatógrafo com os compostos BTEX}

Cálculos do volume para diluição e preparação das soluções

Os volumes de amostra necessários para a diluição e posterior preparação de cada solução foram calculados utilizando a Equação 1 e são mostrados na Tabela 6.

Tabela 6. Volumes de amostras necessários para diluição e posterior preparação de cada solução

\begin{tabular}{lcc}
\hline ponto & Concentração $\left(\mu \mathrm{g} \mathrm{mL}^{-1}\right)$ & Volume de amostra $(\mathrm{mL})$ \\
\hline 1 & 1,0 & 0,5 \\
2 & 0,5 & 5,0 \\
3 & 0,25 & 5,0 \\
4 & 0,125 & 5,0 \\
\hline
\end{tabular}

Após a obtenção dos valores dos volumes necessários para a preparação das soluções de padronização do cromatógrafo, adicionaram-se as alíquotas em balões volumétricos de $10 \mathrm{~mL}$ e diluiuse com metanol. Injetaram-se as amostras para determinar o tempo de retenção e a área do pico para cada composto (para a construção das curvas de padronização).

\section{Determinação do tempo de retenção para os BTEX}

Os valores obtidos (em termos da média e incerteza da média) na determinação do tempo de retenção de cada um dos compostos orgânicos voláteis, benzeno, tolueno, etilbenzeno, o-xileno, mxileno e p-xileno (BTEX) são apresentados na Tabela 7.

Tabela 7. Tempo de retenção dos compostos orgânicos voláteis

\begin{tabular}{lcc}
\hline Composto & $\begin{array}{c}\text { Tempo de } \\
\text { retenção }(\mathrm{min})\end{array}$ & $\begin{array}{c}\text { Estimativa do } \\
\text { desvio padrão }\end{array}$ \\
\hline Benzeno & $7,28 \pm 0,01$ & 0,008 \\
Tolueno & $9,78 \pm 0,02$ & 0,012 \\
Etilbenzeno & $12,41 \pm 0,02$ & 0,012 \\
m-xileno & $12,62 \pm 0,02$ & 0,016 \\
p-xileno & $13,37 \pm 0,02$ & 0,016 \\
o-xileno & $15,33 \pm 0,02$ & 0,015 \\
\hline
\end{tabular}


Com a construção das curvas de padronização, observou-se que o intervalo escolhido guarda excelente relação linear com o sinal analítico, denotado pelos valores de coeficiente de correlação próximos de 1 apresentados na Tabela 8 .

Tabela 8. Equações das curvas de padronização, coeficientes de correlação e intervalo de concentrações

\begin{tabular}{|c|c|c|c|}
\hline Compostos & $\begin{array}{c}\text { Intervalo } \\
\text { de concentrações } \\
\left(\mu \mathrm{g} \mathrm{mL} L^{-1}\right)\end{array}$ & Equações & $\begin{array}{l}\text { Coeficientes } \\
\text { de correlação }\end{array}$ \\
\hline Benzeno & 0,125 a 1 & $\begin{aligned} Y & =6113,7 x \\
& +414,4\end{aligned}$ & 0,9923 \\
\hline Tolueno & 0,125 a 1 & $\begin{aligned} Y & =5826,3 x \\
& -485,8\end{aligned}$ & 0,9979 \\
\hline Etilbenzeno & 0,125 a 1 & $\begin{array}{c}Y=8861,2 x \\
-1034,7\end{array}$ & 0,9947 \\
\hline m-xileno & 0,075 a 0,6 & $\begin{aligned} Y & =20168,3 x \\
& -1366,4\end{aligned}$ & 0,9958 \\
\hline p-xileno & 0,037 a 0,3 & $\begin{array}{c}\mathrm{Y}=23776,2 \mathrm{x} \\
-770,8\end{array}$ & 0,9934 \\
\hline o-xileno & 0,012 a 0,1 & $\begin{array}{c}Y=137822,3 x \\
-1850,5\end{array}$ & 0,9940 \\
\hline
\end{tabular}

Y - área do pico do composto; $\mathrm{x}$ - concentração do composto.

Análise das emissões de BTEX provenientes do motor movido a diesel e à mistura diesel/biodiesel-Soyminas (B10)

Como poderia ocorrer co-eluição de hidrocarbonetos aromáticos com os saturados, posteriormente, foram feitas análises por espectrometria de massas acoplada à cromatografia (CG-EM) empregando o modo SIM, coluna DB-5 e programa de temperatura do forno de $60{ }^{\circ} \mathrm{C}$ durante $1 \mathrm{~min}$ e com uma razão de aquecimento de $7{ }^{\circ} \mathrm{C} \min ^{-1}$ até a temperatura de $165{ }^{\circ} \mathrm{C}$.

Os resultados obtidos por CG-EM foram muito próximos aos observados por CG-FID, garantindo assim uma maior confiabilidade na identificação e quantificação dos compostos de interesse (BTEX).

Comparando-se os resultados dos ensaios cromatográficos das emissões de motor movido a óleo diesel (Tabela 9) e das emissões do motor movido a B10 (Tabela 10), nota-se uma redução da concentração de benzeno e etilbenzeno nas emissões do B10, comparativamente às emissões do óleo diesel. Isso evidencia um benefício ambiental que a adição de biodiesel ao óleo diesel pode promover.

A Tabela 9, em comparação com a Tabela 10, mostra a redução nas emissões para o etilbenzeno e benzeno, evidenciando-se uma redução na concentração dessas duas substâncias.

É importante observar que para o benzeno houve uma redução da

Tabela 9. Emissões de BTEX do motor a diesel variando-se o parâmetro momento de força (rotação: $2500 \mathrm{rpm}$ )

\begin{tabular}{lccc}
\hline Parâmetro & \multicolumn{3}{c}{ Momento de força (N m) } \\
& 36,1 & 45,2 & 57,6 \\
\hline Composto & \multicolumn{3}{c}{ Concentração $\left(\mu \mathrm{g} \mathrm{mL}^{-1}\right)$} \\
\hline Benzeno & $0,323 \pm 0,085$ & $0,375 \pm 0,044$ & $0,399 \pm 0,014$ \\
Tolueno & $0,190 \pm 0,019$ & $0,237 \pm 0,019$ & $0,376 \pm 0,120$ \\
Etilbenzeno & $0,365 \pm 0,083$ & $0,373 \pm 0,109$ & $0,380 \pm 0,136$ \\
m-xileno & $0,159 \pm 0,070$ & $0,174 \pm 0,089$ & $0,259 \pm 0,057$ \\
p-xileno & $0,151 \pm 0,068$ & $0,159 \pm 0,070$ & $0,170 \pm 0,090$ \\
o-xileno & ND & ND & ND \\
\hline
\end{tabular}

ND - não detectado $\mathrm{N}=6$
Tabela 10. Emissões de BTEX do motor à mistura diesel/biodieselSoyminas (B10) variando-se o parâmetro momento de força (rotação: $2500 \mathrm{rpm}$ )

\begin{tabular}{lccc}
\hline Parâmetro & \multicolumn{3}{c}{ Momento de força (N m) } \\
& 36,1 & 45,2 & 57,6 \\
\hline Composto & \multicolumn{4}{c}{ Concentração $\left(\mu \mathrm{g} \mathrm{mL} \mathrm{mL}^{-1}\right)$} \\
\hline Benzeno & $0,274 \pm 0,077$ & $0,294 \pm 0,031$ & $0,305 \pm 0,101$ \\
Tolueno & $0,215 \pm 0,054$ & $0,226 \pm 0,027$ & $0,280 \pm 0,067$ \\
Etilbenzeno & $0,339 \pm 0,066$ & $0,357 \pm 0,090$ & $0,375 \pm 0,049$ \\
m-xileno & $0,120 \pm 0,045$ & $0,228 \pm 0,103$ & $0,271 \pm 0,123$ \\
p-xileno & $0,162 \pm 0,033$ & $0,167 \pm 0,046$ & $0,200 \pm 0,052$ \\
o-xileno & $\mathrm{ND}$ & $\mathrm{ND}$ & $\mathrm{ND}$ \\
\hline ND - não detectado & & & $\mathrm{N}=6$
\end{tabular}

concentração em termos de porcentagem de 14,5 a $24,5 \%$ comparando-se dentro das três condições citadas. Ainda mais, nota-se que o valor da concentração do benzeno está abaixo do limite de exposição de $1 \mu \mathrm{g} \mathrm{mL}{ }^{-1}$ recomendado. ${ }^{31}$ Embora com um valor de concentração abaixo de $1 \mu \mathrm{g} \mathrm{mL}^{-1}$ esta redução (tanto na utilização do diesel quanto na mistura diesel-biodiesel) é significativa pois, considerando-se longos tempos, mesmo estando abaixo da concentração limite, a exposição aos gases poluentes pode ser potencialmente prejudicial ao ambiente e também à saúde de humanos e animais.

Como se pode observar nas Tabelas 9 e 10 tem-se um aumento na concentração de todas as substâncias quando se aumenta o momento de força tanto para o motor alimentado a diesel quanto para os dois tipos de mistura. Isto ocorre porque com o aumento no momento de força, há maior injeção de combustível e, conseqüentemente, maiores serão as emissões dos gases poluentes. Além disto, observa-se que para o tolueno houve uma diminuição na concentração das emissões quando foi utilizado o óleo diesel comparativamente com o $\mathrm{B} 10$, nas condições de momento de força de 45,2 e $57,6 \mathrm{~N} \mathrm{~m}$. O aumento na concentração do p-xileno pode ser considerado dentro dos limites do intervalo de confiança da média. Entre os xilenos, somente o o-xileno não foi detectado nas amostras de gases analisadas.

Entretanto, para o m-xileno tem-se redução na concentração apenas quando se emprega o óleo diesel, comparativamente com o motor alimentado com a mistura diesel/biodiesel-Soyminas na condição de 36,1 $\mathrm{N}$ m, como descrevem as Tabelas 9 e 10.

Quando se comparam os valores de concentração de BTEX emitidos pelo motor movido a diesel com o motor movido com os dois tipos de mistura observa-se uma redução apreciável nas emissões. Também se observa esta redução em vários trabalhos citados na literatura. ${ }^{26,32-35}$

\section{CONCLUSÕES}

Nos testes feitos de análise de gases emitidos por motores de combustão interna por cromatografia gasosa, notou-se que os resultados mostraram uma boa linearidade na metodologia empregada.

Pelos resultados obtidos (utilizando-se o motor de ignição por compressão) observou-se que a adição de um combustível alternativo (biodiesel) a um combustível tradicional (diesel) promove a redução das emissões provenientes do motor de ignição por compressão, como é citado em vários trabalhos na literatura.

Para o benzeno obteve-se uma redução média da concentração de até $24,5 \%$ nas três condições de momento de força utilizadas nos experimentos, mostrando assim a eficiência da adição de biodiesel ao diesel. Apesar de se ter obtido um valor de concentração abaixo de $1 \mu \mathrm{g} \mathrm{mL}^{-1}$ tanto na utilização do diesel quanto na 
utilização da mistura diesel-biodiesel, esta redução é bastante significativa por ser o benzeno um composto comprovadamente carcinogênico. Então, as pessoas poderão estar expostas a menores concentrações deste composto no ambiente e, assim, poderão diminuir os riscos de doenças como o câncer.

Para os outros compostos, exceto o etilbenzeno que teve redução nas três condições, tem-se redução em algumas condições de momento de força, como para o tolueno $(45,2$ e $57,6 \mathrm{~N} \mathrm{~m})$ e, ainda, para o m-xileno, a redução ocorreu somente na condição de $36,1 \mathrm{~N} \mathrm{~m}$. Isto também é importante, pois, mesmo que não sejam considerados carcinogênicos (ainda estão sendo feitos estudos para comprovar este fato), são substâncias neurotóxicas e/ou mutagênicas. ${ }^{3}$

Além disso, observou-se que houve aumento na concentração do p-xileno nas três condições utilizadas, isto pode ser considerado dentro dos limites do intervalo de confiança da média, não sendo tão significativo. E, finalmente, não foi detectado o-xileno em nenhuma das condições investigadas.

\section{AGRADECIMENTOS}

Ao suporte financeiro do CNPq; ao L. A. Valentin e D. W. Miwa pelas valiosas sugestões e ajuda neste trabalho; à empresa SoyminasBiodiesel pelo fornecimento de biodiesel; ao Núcleo de Engenharia Térmica e Fluidos pela infra-estrutura oferecida.

\section{REFERÊNCIAS}

1. Ciccioli, P.; Brancaleoni, E.; Cecinato, A.; Di Palo, C.; Buttini, P.; Liberti, A.; J. Chromatogr. 1986, 351, 451 .

2. http://www.cetesb.com.br, acessada em Dezembro 2003

3. http://www.epa.gov/ttn/atw/allabout.html\#effects, acessada em Março 2004.

4. Martins, L. C.; Latorre, M. R. D. O.; Cardoso, M. R. A.; Rev. Saúde Pública 2002, 36, 88 .

5. Andrade, F.; Orsini, C.; Maenhaut, W.; Atmos. Environ. 1994, 28, 2307.

6. Souza, S. R.; Vasconcellos, P. C.; Carvalho, L. R. F.; Atmos. Environ. 2000, 33, 2563

7. Peterson, C. E.; Mickler, R. A.; J. Environ. Qual. 1994, 23, 257.

8. Massagardi, M.; Hart World Fuels Conference Latin American \& the Caribbean, Rio de Janeiro, Brasil, 2004.
9. Sher, E.; Handbook of Air Pollution from Internal Combustion Engines: Pollutant Formation and Control, Academic Press: San Diego, 1998.

10. http://www.chevron.com/prodserv/fuels, acessada em Março 2004

11. Onursal, B.; Gautam. S.P.; World Bank Technical Paper 1997, n.373.

12. http://www.europarl.eu.int/commonpositions/2002/pdf/c5-0585-02_pt.pdf, acessada em Dezembro 2004.

13. http://www.biodiesel.org/resources/fuelfactsheets/default.shtm, acessada em Setembro 2005.

14. Ramos, L. P.; Anais do Congresso Brasileiro de Soja, Londrina, Brasil, 1999.

15. htpp://www.epa.gov, acessada em Outubro 2006.

16. Freedman, B.; Butterfield, R. O.; Pryde, E. H.; J. Am. Oil Chem. Soc. 1986, 63, 1375.

17. Plank, C.; Lorbeer, E.; J. Chromatogr. 1994, 683, 95.

18. Mittelbach, M.; Roth, G.; Bergmann, A.; Chromatographia 1996, 42, 431.

19. Gelbard, G.; Brès, O.; Vargas, R. M.; Vielfaure, F.; Schuchardt, U.; J. Am Oil Chem. Soc. 1995, 72, 1239.

20. Arellano, D. B.; Óleos \& Grãos 1993, 13, 10

21. Lima, J. R.; Gonçalves, L. A. C.; Anais do Simpósio sobre Qualidade Tecnológica e Nutricional de Óleos e Processos de Frituras da Sociedade Brasileira de Óleos e Gorduras, São Paulo, Brasil, 1997.

22. Nye, M. J. T. W.; Williamson, S.; Deshpande, J. H.; J. Am. Oil Chem. Soc. 1983, 60, 598.

23. Herrera, C. G.; Grasas y Aceites 1995, 46, 121.

24. Ministério da Indústria e do Comércio; Óleos Vegetais - Experiência de Uso Automotivo Desenvolvida pelo Programa OVEG I, Brasília, Brasil, 1985.

25. Ministério da Indústria e do Comércio; Produção de Combustíveis Líquidos a partir de Óleos Vegetais, Brasília, Brasil, 1985.

26. Chang, Y. Z. D.; Gerpen, V. H. J.; Lee, I.; Johnson, A. L.; Hammond, G. E.; Marley, J. S.; J. Am. Oil Chem. Soc. 1996, 73, 1549.

27. Clark, S. J.; Wagner, L.; Schrock, M. D.; Piennaar, P. G.; J. Am. Oil Chem. Soc. 1984, 61, 1632

28. Masjuk, H.; Sapuan, M. S.; J. Am. Oil Chem. Soc. 1995, 12, 609.

29. Laurindo, J. C.; Anais do Congresso Internacional de Biocombustíveis Líquidos, Curitiba, Brasil, 1998.

30. Mittelbach, M.; Tritthart, P.; J. Am. Oil Chem. Soc. 1988, 65, 1185.

31. http://www.osha.gov, acessada em Abril 2005.

32. Ali, Y.; Hanna, M. A.; Bioresour. Technol. 1994, 50, 153.

33. Mcdonnell, K.; Ward, S., Leahy, J. J.; Mcnulty, P.; J. Am. Oil Chem. Soc. 1999, 76, 539.

34. Peterson, C.; Reece, D.; Trans. ASAE 1996, 39, 805

35. Scharmer, K. Em Biodiesel from set-aside land. A story of success? Sustainable agriculture for food, energy and industry; Scharmer, K., ed.; James \& James: London, 1998, p. 844. 